\title{
ПРОГРАММА ВОСТОЧНОЕ ПАРТНЁРСТВО НАКАНУНЕ ДЕСЯТИЛЕТИЯ ${ }^{1}$
}

Аннотация. В статье анализируется развитие программы Восточное партнёрство Европейского союза, со дня принятия которой в мае 2019 г. исполнится 10 лет. Программа стала развитием Европейской политики соседства в условиях, когда членами ЕС стали иентральноевропейские государства. 3 а 10 лет состоялось пять саммитов, посвящённых согласованию позиций государств-членов и новых независимых государств - наследников СССР. Решающими были первый и третий саммит. Второй саммит констатировал скорее отсутствие интереса к программе со стороны западноевропейских государств. Четвёртую встречу лидеров вовлечённых в программу государств назвали саммитом неопределённости. Пятый саммит, состоявшийся в 2017 г., поставил задачи «нового поколения», сформировавшиеся в «постукраинском мире».

Ключевые слова: Европейский союз, Восточное партнёрство, расширение, Политика соседства, программа адаптачии, внешняя политика.

На 2019 г. приходится новая череда центральноевропейских знаковых юбилеев, один из которых достанется программе Восточное партнёрство. Десять лет назад, 7 мая 2009 г. на саммите Евросоюза в Праге, во время председательства в Совете ЕС Чехии, Европейским союзом была принята разработанная польскими и шведскими представителями программа взаимодействия с расположенными на восточных границах ЕС государствами - наследниками распавшегося СССР: Белоруссией, Украиной, Молдавией, Арменией, Азербайджаном и Грузией. Этот проект стал частью Политики соседства ЕС в отношении государств, примыкающих к Евросоюзу с востока. И хотя Россия также имеет границу с Европейским союзом, она в данную программу приглашена не была. Это стало одной из причин недоверия Москвы к проекту, который, по её мнению, непосредственно пересекался с её собственными намерениями построения новых отношений с бывшими союзными республиками. Для шести государств постсоветского пространства проект был привлекателен тем, что в отличие от российских вариантов, выдвигал чёткую стратегию, что и как необходимо делать для того, чтобы приблизиться к европейским стандартам в экономическом, политическом, гуманитарном отношениях.

На сегодняшний день прошло пять саммитов Восточного партнёрства. О них, как и о программе в целом, мы подробно писали ранее ${ }^{2}$. Наибольшую известность в силу последст-

(C) Шииелина Любовь Николаевна - доктор исторических наук, главный научный сотрудник, руководитель Отдела исследований Центральной и Восточной Европы Института Европы РАН. Adpec: 125009, Россия, Москва, ул. Моховая, д. 11, стр. 3. E-mail: 1.shishelina@gmail.com.

DOI: http://dx.doi.org/10.15211/vestnikieran620182635

${ }^{1}$ Статья подготовлена при финансовой поддержке РФФИ в рамках проекта № 17-07-00016 «Россия и Центральная Европа: проблемы и перспективы взаимоотношений в условиях мирового политического кризиса»".

${ }^{2}$ Вишеградская Европа: откуда и куда? Два десятилетия по пути реформ в Венгрии, Польше, Словакии и Чехии / под ред. Л.Н. Шишелиной. М.: Весь Мир, 2010. Любовь Шишелина, Вишеградская группа и Восточное партнёрство / Вишеградский ежегодник №2. Приложение к журналу «Современная Европа» №4, 2013; Любовь Шишелина. Венгерский подход к Восточному партнёрству // Вишеградский ежегодник №2. Приложение к журналу «Современная Европа» №4, 2013; Председательство Латвии в ЕС - 2015: «Восточное партнёрство» вместо или 
вий международного масштаба стал Вильнюсский саммит, прошедший в ноябре 2013 г., где главным фигурантом стала Украина, и после которого фактически началось нынешнее глобальное противостояние. Следовавшие за ним саммиты 2015 г. в Риге и 2017 г. в Брюсселе отличались некоторым откатом в амбициях, осторожностью в формулировках, а также нарастающим прояснением в позициях сторон относительно перспектив участия в программе. Это, в частности, отразилось в конкретизации планов, заменивших достаточно расплывчатые формулировки первого, «доукраинского» или «довильнюсского» этапа программы. Открывая последний саммит, председатель Евросовета Д. Туск подчеркнул главное актуальное намерение - «Мы хотим укрепить сотрудничество Восточного партнёрства в ряде конкретных областей, таких как малые и средние предприятия, цифровая экономика, инвестиции в широкополосную связь, а также инвестиции в транспортные, энергетические и инфраструктурные проекты. Список длинный. Но прежде всего мы хотим укрепить связи между нашими гражданами и оказать большую поддержку гражданскому обществу» ${ }^{1}$.

\section{Первый этап развития проекта}

Политика Восточного партнерства разрабатывалась в период общего ухудшения отношений России и Евроатлантического сообщества: после ветирования Польшей нового базового соглашения с Россией в 2006 г. и попыток Литвы последовать её примеру год спустя; на фоне активизации антироссийской позиции ЕС по грузино-осетинскому конфликту в 2008 г. и в разгар экономического кризиса. Все эти факторы в той или иной степени не могли не отразиться в формирующемся новом «восточном» курсе Евросоюза. Намечавшаяся программа действий в итоге должна была привести к укреплению государственного фундамента новых независимых государств, их большей независимости от России (особенно это касается раздела по диверсификации энергии) и ускорению сближения с ЕС. Стратегически Европейский союз продолжал линию на формирование вокруг себя кольца лояльных государств, которые могли служить расширению его рынка, сферы влияния и одновре́менно - внешним кольцом безопасности. Собственно, уже в проектном документе Восточное партнёрство называлось «специальным измерением Европейской политики соседства» ${ }^{2}$.

В январе 2009 г. представленная на обсуждение в парламент программа была остро раскритикована евродепутатами ${ }^{3}$. Стало ясно, что в ЕС нет единого представления о том, как строить отношения с соседними государствами к востоку, и следует ли увязывать новую программу с перспективой дальнейшего расширения Евросоюза ${ }^{4}$. Основные сомнения были свя-

вместе с Россией / Общий доклад под. ред. О. Гоман-Голутвиной. РАПИ - МГИМО, 2014 г:. Гаман-Голутвина О.В., Пономарева Е.Г., Шишелина Л.Н.. «Восточное партнёрство»: борьба сценариев развития // Полис №5, 2014. С. 20-40. 1,5 п.л.; Гаман-Голутвина О.В., Пономарева Е.Г., Шишелина Л.Н. Проект Восточного партнёрства «до» и «после» Майдана // Вестник аналитики. №57 (3-2014), № 58 (4-2014); «Вишеградская Европа и Россия: испытание Украиной». Научный доклад под. ред. Л.Н. Шишелиной, РСМД, 2015; Шишелина Л.Н., Глава 16. Восточное партнёрство // Европа XXI века. Новые вызовы и риски / Под общей редакцией Ал.А. Громыко, В.П. Фёдорова. - М., СПб.: Нестор-История, 2017; Shishelina L. Russia, the West, and Eastern Europe // The Russia File: Russia and the West in an Unordered World. Ed.: Daniel S. Hamilton and Stefan Meister/ Washington, DC: Center for Transatlantic Relations, 2017.

${ }^{1}$ Eastern Partnership summit, 24/11/2017. Main Results. URL: https://www.consilium.europa.eu/en/meetings/interna tional-summit/2017/11/24/

${ }^{2}$ Communication from the Commission... Op. cit. P. 2.

${ }^{3}$ Bulletin Quotidien Europe №9822. Brussels. 20.01.2009.

${ }^{4}$ Одни упрекали программу в отсутствии амбициозности, другие, как депутат от Румынии А. Северин, - в стремлении продать Евросоюзу пустую коробку в красивой упаковке. Представитель Британии Ч. Таннок увидел в предложении Польши и Швеции несоответствие реалиям, выражающееся, в частности, по его мнению, в том, что страны, рассматриваемые в рамках этой программы как регион, на самом деле таковым себя не считают и желают выстраивать с Евросоюзом исключительно двусторонние отношения. В то же время депутат от Литвы В. Ландсбергис отметил, что программа не обеспечивает главного - защиты стран - объектов этой политики от Научно-аналитический вестник ИЕ РАН, 2018, №6 
заны с тем, что поначалу в ЕС доминировало представление о том, что государства, в отношении которых разрабатывалась эта политика, представляют собой скорее однородное объединение, движимое сходными целями и интересами. Тем не менее уже ко второму саммиту выяснилось, что это не так, и программа нуждается в существенной доработке.

По мнению участников и прессы ${ }^{1}$, второй саммит Программы ВП ${ }^{2}$, прошедший в Варшаве 29-30 сентября 2011 г., вызвал интерес гораздо меньше ожидавшегося. Также оценивались и результаты саммита. Большинство аналитиков назвали главной причиной озабоченность Европы финансовым и долговым кризисом и революции в арабских странах, также являющихся объектом политики партнёрства ЕС. Среди лидеров ведущих стран единственной, кто посетил саммит, была немецкий канцлер Ангела Меркель. Президент Франции Саркози предпочёл присутствовать на открытии автомагистрали в Марокко. Власти Белоруссии и вовсе проигнорировали саммит. Таким образом, собравшиеся лишь несколько продвинулись по пути декларации о намерениях подписать с Украиной соглашение об ассоциации. Было принято решение о подготовке подобных соглашений с Молдавией и Грузией. Впервые на саммите кавказские государства были признаны европейскими - это особенно оценила азербайджанская делегация. Общий объём финансирования программы Восточное партнёрство было решено в бюджете 2014-2020 гг. довести до 2 млрд евро. К тому же Польша заявила о собственной инициативе добавить свой миллион в фонд технической помощи странам ВП. Одновре́менно обнаружились расхождения в целях программы и между странами ЕС и между странами - объектами программы. В частности, стало очевидным, что не все страны желали принятия новых членов и новой волны расширения Европейского союза.

Тем не менее программа продвигалась. Неуспехи на одних направлениях компенсировались на других. Так, на знаменитом отказом Украины от подписания Соглашения об ассоциации Вильнюсском 2013 г. саммите были свои «компенсирующие» итоги - парафирование Соглашений об ассоциации с ЕС Молдавией и Грузией ${ }^{3}$. Также в Вильнюсе было подписано соглашение об упрощении визового режима с Азербайджаном и снижении визовых пошлин для его граждан. В целом, как отметили Херман Ван Ромпей и Жозе Мануэл Баррозу, саммит стал важной точкой для оценки результатов всей восточноевропейской политики Евросоюза за последние годы. Он дал шанс выбрать новые конкретные стратегические шаги по улучшению политики соседства в Восточной Европе вплоть до 2015 г., т.е. до саммита в Риге под эгидой латвийского президентства в Совете ЕС.

Подводя итог председательству Литвы в Совете ЕС, президент Даля Грибаускайте сказала в Европарламенте 15 января 2014 г.: «Результатом Вильнюсского саммита стала провокация исторических перемен, давших новый импульс Восточному партнёрству. Украина больше никогда не будет прежней» ${ }^{4}$. В этом она оказалась права.

посягательств со стороны России. Bulletin Quotidien Europe №9822. Brussels. 20.01.2009.

${ }^{1}$ Siarkiewicz Paweł, European press on the Eastern Partnership Summit in Warsaw / Easternpartnership.org. October 7 , 2009. URL: http://www.easternpartnership.org/ru/publication/2011-10-07/european-press-eastern-partnership-summitwarsaw.

2 Здесь и далее - ВП - Восточное партнёрство.

${ }^{3}$ Новый президент Грузии Г. Маргвелашвили ещё 23 ноября 2013 г., буквально на следующий день после отказа Украины подписывать Соглашение об ассоциации, подтвердил, что его страна будет подписывать договор о сотрудничестве с ЕС, назвав этот шаг стратегическим выбором, поддержанным гражданами Грузии, который не изменится даже при давлении извне. В этот же день молдавский премьер-министр Ю. Линкэ также объявил, что его страна продолжит интеграцию с ЕС, а пятью днями ранее в интервью украинским телеканалам он заявил, что подобные шаги были необратимым следствием твёрдой политики Молдавии по модернизации страны. См.: Bulletin Quotidien Europe №10974. Brussels. 30.11.13.

${ }^{4}$ Speech by President Dalia Grybauskaite to the European Parliament. 15 January 2014. [Электронный pecypc]. URL: http://www.eu2013.1t/en/news/statements/speech-by-president-dalia-grybauskaite-to-the-european-parliament. 
Ответственные чиновники Евросоюза отмечали, что отказываться от подписания Соглашения об ассоциации с Украиной ЕС не намерен, а приостановка Соглашения - это не то же самое, что отказ от него ${ }^{1}$. Комиссар по Восточному партнёрству, чешский дипломат Штефан Фюле после провала подписания Соглашения с Украиной сделал заявление, что дверь остаётся открытой, и ЕС возобновит все приготовления, как только Украина сама будет готова к возвращению на путь экономической интеграции с Евросоюзом и лидеры страны проявят надлежащую политическую волю.

Эту «волю» продемонстрировал новый президент Украины Петр Порошенко, подписав 27 июня 2014 г. на саммите ЕС в Брюсселе экономическую часть Соглашения об ассоциации с Европейским союзом, предполагающую создание зоны свободной торговли. Символично, что П. Порошенко подписал документ ручкой, подаренной президентом Литвы Далей Грибаускайте Виктору Януковичу 29 ноября 2013 г. на саммите Восточного партнерства в Вильнюсе именно в надежде на подписание Соглашения об ассоциации, которое тогда так и не состоялось.

\section{Восточное партнёрство в «поствильнюсский период»}

Сокрушительная неудача с Украиной не послужила приостановке программы, однако стала поводом для некоторого переосмысления всей «восточной политики» ЕС. На фоне введения вслед за США антироссийских санкций - как ответной меры на присоединение Крыма в период полного политического хаоса на Украине Евросоюз продолжал подготовку и к очередному саммиту Восточного партнёрства, который должен был состояться в первой половине 2015 г. в Риге.

В продолжение программы Восточного партнёрства Латвия предложила налаживание политического диалога и экономического сотрудничества между ЕС и Белоруссией, считая роль этой страны ключевой в урегулировании украинского кризиса ${ }^{2}$. Другим приоритетом Восточного партнёрства была названа Армения. Считалось, что майский саммит ВП в Риге может стать идеальным поводом для запуска переговоров относительно нового соглашения EC - Армения ${ }^{3}$. Параллельно не менее важным направлением для латвийского председательства стала заявленная готовность к развитию всестороннего сотрудничества с Казахстаном, не входившим прежде в программу Восточного партнёрства ${ }^{4} .20$ января 2015 г. в Брюсселе был парафирован текст соглашения о расширенном партнёрстве и сотрудничестве, которое, как полагали в Европейском союзе, в большей степени могло бы способствовать политическому и социальному развитию Казахстана по пути демократизации и реформ. Однако из поля зрения аналитиков не могло ускользнуть совпадение этой активности с преддверием президентских выборов в Казахстане. В марте 2015 г. состоялось последнее перед майским саммитом партнёрства заседание глав государств и правительств ЕС, по завершении которого Совет ЕС сделал заявление о намерении Евросоюза усилить дифференциацию в отношениях с каждым из шести партнёров. В коммюнике по результатам встречи это формулировалось следующим образом: особые усилия должны быть направлены на продвижение сотрудниче-

\footnotetext{
${ }^{1}$ Ibid.

${ }^{2}$ По мнению министра иностранных дел Латвии Э. Ринкевича, ЕС мог бы оказать Минску большую поддержку в подготовке присоединения к ВТО, модернизации страны, а также в решении проблем окружающей среды. Однако, как подчеркнул министр, возможный прогресс в данном случае не означает, что ЕС откажется от своей точки зрения в отношении ущемления прав меньшинств в Белоруссии, необходимости освобождения всех политических заключённых и не перестанет оказывать давления в этих вопросах на белорусское руководство. См.: Bulletin Quotidien Europe №11227. Brussels. 10.01.15.

${ }^{3}$ Bulletin Quotidien Europe №11234. Brussels. 21.01.15.

${ }^{4}$ Bulletin Quotidien Europe №11235. Brussels. 22.01.15.
}

Научно-аналитический вестник ИЕ РАН, 2018, №6 
ства в построении государства и усиление демократических институтов на востоке Европы ${ }^{1}$

Состоявшийся 21-22 мая 2015 г. в Риге очередной (четвёртый) саммит Восточного партнёрства завершился без каких-либо сенсаций. В отношении ожидавшихся некоторыми странами планов дальнейшего расширения такие «тяжеловесы» европейской политики, как Ангела Меркель, Жан-Клод Юнкер и Дональд Туск чётко дали понять, что ничего подобного в ближайшее время не предвидится. Обращаясь к депутатам бундестага перед отъездом в Ригу, А. Меркель заявила, что ВП является не инструментом расширения Евросоюза, а лишь инструментом сближения, и не следует давать партнёрам напрасных надежд, которые впоследствии тяжело будет реализовать. Ж.-К. Юнкер отметил, что формат данного саммита не подразумевает переговоров о присоединении к Европейском союзу, так как страны-партнёры еще не готовы к вступлению, а страны-члены - к расширению. Д. Туск, подводя итоги саммита, констатировал, что странам Восточного партнёрства никто не гарантировал автоматического вступления в Евросоюз после подписания договоров об ассоциации. Даже молдавский президент Николай Тимофти объявил, что из-за украинского кризиса его страна пока не станет подавать заявку на вступление в ЕС, несмотря на то, что летом 2014 г. он официально выразил намерение сделать это в 2015 г.

Впрочем, лидеры ЕС всё же немного смягчили ситуацию, в очередной раз пообещав безвизовый режим Грузии и Украине. При этом Ж.-К. Юнкер лично заверил, что перечень проблем, над которыми этим странам предстоит работать перед отменой виз, уже передан их правительствам, и Еврокомиссия будет готова оценить качество выполнения этого «домашнего задания» к 15 декабря 2015 г. Если результат будет удовлетворительным, Украина и Грузия смогут пользоваться безвизовым режимом уже с начала 2016 г. По итогам Рижского саммита была принята совместная 13-страничная декларация, состоящая из тридцати пунктов, где подробно перечисляются планы и сферы взаимодействия между странами ЕС и восточными партнёрами. Ничего о санкциях против России на саммите, вопреки ожиданиям многих, сказано не было. Лишь в итоговой декларации Европейский союз подтвердил свою позицию касательно «аннексии» Крыма и Севастополя, а также территориальной целостности Украины $^{2}$. В Риге же высшими финансовыми представителями Европейского союза и Украины был подписан Меморандум о взаимопонимании в отношении третьего пакета макрофинансовой помощи ЕС Украине в размере 1,8 млрд евро ${ }^{3}$.

\section{Брюссельский саммит и «20 задач» Восточного партнёрства}

Пятый саммит Восточного партнёрства состоялся в Брюсселе в ноябре 2017 г. В принятой Декларации, ЕС подтвердил свою приверженность поддержке территориальной целостности, независимости и суверенитета всех своих партнёров ${ }^{4}$. В виду актуальной ситуации на Украине, участники саммита призвали активизировать усилия по содействию мирному урегулированию открытых конфликтов в регионе на основе международного права.

Они признали европейские устремления и европейский выбор партнёров, которые подписали соглашения об ассоциации с ЕС, а именно с Грузией, Республикой Молдова и Украи-

\footnotetext{
${ }^{1}$ Европейский совет также с нетерпением ожидал скорейшей ратификации всеми государствами-членами договоров о Всеобъемлющей и глубокой зоне свободной торговли (DCFTA) с Грузией, Молдавией и Украиной. В рамках DCFTA Евросоюз декларировал намерения инвестировать порядка 1,5 млрд евро в малые и средние предприятия этих государств. См.: Bulletin Quotidien Europe №11232. Brussels. 17.01.15.

2 Joint Declaration of the Eastern Partnership Summit, Riga, 21-22 May 2015. P. 2.

3 Данный документ посвящён важным экономическим и структурным реформам в шести следующих областях: государственные финансы, управление и прозрачность, деловой климат, энергетический сектор, система социальной безопасности и финансовый сектор.

${ }^{4}$ Joint Declaration of the Eastern Partnership Summit. Brussels, 24 November 2017. URL: https://www.consilium. europa.eu/en/meetings/international-summit/2017/11/24/\#
} 
ной; в то же время признавая право других партнёров выбирать уровень амбиций, к которому они стремятся в своих отношениях с Евросоюзом. «Не должно быть никаких сомнений в том, что наше общее будущее заключается в готовности ЕС открыть политику ЕС для наших партнёров. И я могу подтвердить, что мы готовы это сделать»- сказал по завершении саммита председатель Европейского союза Дональд Туск.

В Декларации также подчёркивались главные устремления программы ВП:

- повышение эффективности управления;

- улучшение и повышение безопасности транспортных связей;

- соблюдение энергетической безопасности;

- дальнейшая поддержка независимых СМИ и борьба с дезинформацией;

- участие лидеров в развитии мобильности и расширении прав и возможностей молодёжи.

В рамках саммита ЕС и Армения подписали Всеобъемлющее и расширенное соглашение о партнёрстве и заключили авиационное соглашение. Кроме того, на восточных партнёров распространялась Трансъевропейская транспортная сеть ЕС (TEN-T).

Главным документом стала, однако, программа, озаглавленная «20 deliverables for 2020» (20 заданий к 2020 г. $)^{1}$, в которой подводились итоги предыдущей деятельности в рамках программы и намечались задачи, которые предстояло выполнить к 2020 г.

Интересна сама структура документа. Он оформлен в виде таблицы, где в левом столбце указываются достижения за историю существования Программы, а в правом - что ещё предстоит сделать.

Открывает документ констатация того, что за время существования Программы ВП повысилось доверие граждан шести стран к Европейскому союзу. К 2017 г. Евросоюз считали организацией, заслуживающей наибольшего доверия 61\% граждан «шестёрки». Среди задач перечислялись: создание необходимой среды для развития гражданского общества; поддержка плюрализма и независимых медиа; обеспечение гендерного равенства.

Далее достижения и задачи следуют согласно сферам их применения.

Более сильная экономика уже характеризуется тем, что: более 50\% кредитов ЕС перечисляются в национальных валютах; торговля Евросоюза со странами шестёрки после 2016 г. увеличилась в среднем от 15\% (Армения) до 25\% (Украина); достигнут консенсус по введению общего роуминга к 2020 г. Среди задач присутствуют два пункта: гармонизация рынка дигитализации и увеличение внутрирегионального товарооборота.

В области более эффективного управления в рамках Программы удалось достичь цифровизации документооборота в Армении, Грузии и на Украине. Благодаря изменениям в законодательстве о государственной службе удалось достичь больше деполитизации гражданской службы во всех странах, кроме Белоруссии. В число задач вошли: укрепление принципа верховенства закона; имплементация ключевых реформ законодательства; усиление сотрудничества в области безопасности.

Более сильная сплочённость, как следует из документа, характеризуется ростом инвестиций в воплощение региональной железнодорожной и шоссейной логистики к 2020 и 2030 гг.; вводом в действие азербайджано-грузинского отрезка Южного газового коридора; повышением экономичности расхода энергетических ресурсов. На будущее планируется ограничение вредных выбросов в атмосферу; повышение диверсификации биоресурсов и лесооборота.

\footnotetext{
${ }^{1} 20$ Deliverables for 2020: State of play in 2018. URL: file://C:/Users/HP/Desktop/Статья\%20ВП/еap_generic_factsheet_eng_web.pdf.
} 
В Программе стабильного общества успехи представлены открытием Школы Восточного партнёрства в Тбилиси; повышением мобильности молодёжи и студентов (в том числе в рамках программы Erasmus + ); поддержкой программ развития молодёжного предпринимательства и общественной дипломатии; развитием программы Horizon $2020^{1}$. Среди задач можно найти: дальнейшее развитие мобильного партнерства; повышение эффективности и адекватности систем образования.

Если судить по оценкам, наибольшего прогресса удалось достичь в области усиления стратегической коммуникации и развития плюрализма и независимости медиа. В области экономики близкими к завершению оказались сразу три программы: увеличение инвестиций, особенно в малый и средний бизнес; адресная помощь в сфере развития финансовой инфраструктуры; поддержка внутрирегиональной торговли. В сфере управления наибольших успехов удалось достичь в сфере укрепления безопасности. В области сплочённости близкими к завершению оказались логистические программы и укрепление энергобезопасности. А вот общественная стабилизация оказалась практически передовой и смогла отчитаться высокими показателями по всем пунктам: либерализация визового режима; инвестиции в развитие и трудоустройство молодёжи; открытие Школы Восточного партнёрства; интеграция инновационных и исследовательских программ ЕС и ВП.

Однако стоит помнить, что это официальные документы, в которых реальность зачастую несколько приукрашивается. Бросается в глаза то, что при упоминании успехов не делается различий между государствами, находящихся на самом деле на разных ступенях отношений с Европейским союзом, и разрыв между шестью государствами за десять лет скорее увеличился по сравнению со временем их вступления в Программу.

Как отмечает венгерский политолог Габор Штир ${ }^{2}$, в контексте исходных намерений многочисленные слабые места программы обуславливают низкую эффективность её модернизационных возможностей, и в обозримом будущем не стоит рассчитывать на то, что европейская модель будет привита в шести «фокусных государствах». За неимением институциональных условий Евросоюз предлагает восточным партнёрам статус периферии. Те же, «на-ходясь в стадии строительства наций, воспринимают «Восточное партнёрство» скорее в геополитической плоскости, сущность которой, особенно в наиболее успешных «фокусных государствах» в лице Украины и Грузии, однозначно антироссийская. Данный расклад создаёт комфортные условия и для ЕС, который с чистой совестью может «умыть руки» применительно к сдерживанию России». Как заключает Габор Штир, «Восточное партнёрство сильно сдало по сравнению с началом, которое, впрочем, также было не особо динамичным. Каждый видит в программе то, что хочет».

Следующий саммит Восточного партнёрства должен состояться в 2019 г. В октябре 2018 г. в Люксембурге состоялась встреча министров иностранных дел 28 стран ЕС и 6 стран Восточного партнёрства. Комиссар ЕС по делам Восточного партнерства Йоханнес Хан сказал: «Мы должны гордиться нашими достижениями в рамках "20 результатов Восточного партнёрства на 2020 год”. Вместе, шесть восточных партнёров и Евросоюз предприняли конкретные шаги к тому, чтобы сделать наши общества сильнее, экономики региона более устойчивыми и лучше связанными посредством улучшения транспортных связей и инфраструктуры. Заглядывая вперёд, мы будем продолжать совместную работу для достижения конкретных результатов, в частности, в области судебной реформы и обеспечения благоприятных

\footnotetext{
${ }_{1}^{1}$ Восьмая рамочная программа Европейского союза по развитию научных исследований и технологий (РП8).

${ }^{2}$ Штир Габор. ЕС - Восточное партнёрство: разные скорости, разное понимание. 24.11.2017. URL: http://ru. valdaiclub.com/a/highlights/es-vostochnoe-partnyerstvo-raznye-skorosti/
} Научно-аналитический вестник ИЕ РАН, 2018, №6 
условий для независимых средств массовой информации гражданского общества» ${ }^{1}$. На встрече было намечено несколько встреч в рамках программы Восточного партнёрства, а также подготовка к десятилетнему юбилею программы. Для этого в 2019 г. будут удобные предпосылки, поскольку председательство в Совете ЕС выпадет на страны, непосредственно составляющие восточные границы ЕС - Румынию и Финляндию.

\section{$* \quad * \quad *$}

Анализируя эволюцию программы за десять лет со времени её создания следует отметить несколько поворотных моментов. Во-первых, программа преодолела существенные изменения после провала третьего, Вильнюсского саммита. Рижский саммит 2015 г. в этой связи назвали саммитом неопределённости, когда главным вопросом для всего проекта стала дилемма - как развивать отношения дальше? Дальнейший курс программы строился исходя из двух обнажившихся к тому времени очевидностей: 1) нельзя не учитывать, что к востоку от стран Восточного партнёрства находится Россия, также заинтересованная в сохранении связей со странами - объектами партнёрства; 2) в условиях кризиса и различия интересов государств ЕС относительно программы, следует быть более вариативными и гибкими.

На сегодняшний день три страны Программы Восточного партнёрства - Грузия, Украина и Молдавия имеют углублённые соглашения об ассоциации с ЕС и свободный визовый режим. Первыми соглашение об ассоциации с Евросоюзом в июне 2014 г. подписали Грузия и Молдавия, а 1 января 2016 г. вступило в силу Соглашение об углублённой и всеобъемлющей зоне свободной торговли (УВЗСТ) между Украиной и ЕС. Армения на последнем саммите в Брюсселе подписала уже достаточно гибкое Соглашение о всестороннем расширенном партнёрстве, учитывающее и её стремление сохранить равнозначные отношения с Россией. Азербайджан не спешит с фиксированным статусом, но достаточно далеко продвинулся в реальном экономическом взаимодействии с Европейским союзом. Белоруссия продолжает соблюдать наибольшую дистанцию, расценивая её одновре́менно не только как «одну из возможностей», но и как предмет торга с Россией. Данное обстоятельство должно быть учтено Россией в целях избежания ошибок, которые она допустила при строительстве «постсоюзных отношений» с Украиной. Возможно, в этом может помочь возвращение к проекту союзного белорусско-российского государства, провозглашению которого в 2019 г. исполнится 20 лет.

В целом же, линия на снижение конфронтации с Россией, слабо, но наметившаяся по линии Программы ВП в 2016 г. во время председательства Словакии, могла бы подтолкнуть ЕС в дальнейшем к переосмыслению отношений с Россией. Ведь те же самые страны - объекты политики Восточного партнёрства Евросоюза являются и западными соседями России, с которыми у неё за четверть века ещё не окончательно оборвались многоуровневые связи и пересечения интересов. Возможно, что следующим этапом в развитии программы Восточное партнёрство могло бы стать использование возможностей, заложенных в совмещения проектов двух интеграционных пространств (ЕС и ЕАЭС).

\section{Список литературы}

Shishelina L. Russia, the West, and Eastern Europe // The Russia File: Russia and the West in an Unordered World. Ed.: Daniel S. Hamilton and Stefan Meister/ Washington, DC: Center for Transatlantic Relations, 2017.

\footnotetext{
${ }^{1}$ Eastern Partnership Foreign Ministers meeting, 15/10/2018/ URL: https://www.consilium.europa.eu/en/meetings/in ternational-ministerial-meetings/2018/10/15/
} 
Болгова И.В. Актуальный этап Восточной политики ЕС / Современная Европа №7, 2017.

Болгова И.В. «Восточное партнёрство»: неоднозначные результаты / Современная Европа №6, 2016.

«Вишеградская Европа и Россия: испытание Украиной». Научный доклад под. ред. Л.Н. Шишелиной, РСМД, 2015.

Вишеградская Европа: откуда и куда? Два десятилетия по пути реформ в Венгрии, Польше, Словакии и Чехии / под ред.Л.Н.Шишелиной. М.: Весь Мир, 2010.

Гаман-Голутвина О.В., Пономарева Е.Г., Шишелина Л.Н. «Восточное партнёрство»: борьба сценариев развития // Полис №5, 2014. С. 20-40. 1,5 п.л.

Гаман-Голутвина О.В., Пономарева Е.Г., Шишелина Л.Н. Проект Восточного партнёрства «до» и «после» Майдана // Вестник аналитики. №57 (3-2014), №58 (4-2014).

Председательство Латвии в ЕС - 2015: «Восточное партнёрство» вместо или вместе с Россией / Общий доклад под. ред. О. Гоман-Голутвиной. РАПИ - МГИМО, 2014 г.

Шишелина Любовь. Вишеградская группа и Восточное партнёрство / Вишеградский ежегодник №2. Приложение к журналу «Современная Европа» №4, 2013.

Шишелина Любовь. Венгерский подход к Восточному партнёрству // Вишеградский ежегодник №2. Приложение к журналу «Современная Европа» №4, 2013.

Шишелина Л.Н. Глава 16. Восточное партнёрство // Европа XXI века. Новые вызовы и риски / Под общей ред. Ал.А. Громыко, В.П. Фёдорова. - М., СПб.: Нестор-История, 2017.

Штир Габор. ЕС - Восточное партнёрство: разные скорости, разное понимание. 24.11. 2017 // URL: http://ru.valdaiclub.com/a/highlights/es-vostochnoe-partnyerstvo-raznye-skorosti/

\section{References}

Bulletin Quotidien Europe №9822. Brussels. 20.01.2009.

Bulletin Quotidien Europe №10974. Brussels. 30.11.13.

Bulletin Quotidien Europe №11227. Brussels. 10.01.15.

Bulletin Quotidien Europe №11234. Brussels. 21.01.15.

Bulletin Quotidien Europe №11235. Brussels. 22.01.15.

Bulletin Quotidien Europe №11232. Brussels. 17.01.15.

Eastern Partnership summit, 24/11/2017. Main Results. URL: https://www.consilium.europa. eu/en/meetings/international-summit/2017/11/24/

Eastern Partnership Foreign Ministers meeting, 15/10/2018/ URL: https://www.consilium. europa.eu/en/meetings/international-ministerial-meetings/2018/10/15/

Joint Declaration of the Eastern Partnership Summit, Riga, 21-22 May 2015. P. 2.

Joint Declaration of the Eastern Partnership Summit. Brussels, 24 November 2017. URL: https://www.consilium.europa.eu/en/meetings/international-summit/2017/11/24/\#

Speech by President Dalia Grybauskaite to the European Parliament. 15 January 2014. [Электронный ресурc]. URL: http://www.eu2013.1t/en/news/statements/speech-by-president-daliagrybauskaite-to-the-european-parliament.

Stier Gabor. ES - Vostochnoje partnerstvo: raznije skorosti, raznoje ponimanije.24.11.2017 // URL: http://ru.valdaiclub.com/a/highlights/es-vostochnoe-partnyerstvo-raznye-skorosti/

20 Deliverables for 2020: State of play in 2018. URL: file:///C:/Users/HP/Desktop/Статья\% 20ВП/eap_generic_factsheet_eng_web.pdf. 


\section{Ten Ears of the Eastern Partnership}

Author. Lyubov Shishelina, Doctor of Sciences (History), Head of Department for Central and Eastern European Studies, Institute of Europe, Russian Academy of Sciences. Address: 11-3, Mokhovaya str., Moscow, Russia, 125009. E-mail: 1.shishelina@gmail.com.

Abstract. The article analyzes the development of the Eastern partnership program of the European Union, which in May 2019 will celebrate 10 years since its adoption. The program represents the development of the European neighborhood policy under conditions when the Central European States became the EU members. Over the past ten years five summits have been held to coordinate the positions of the member States and the new independent States-the successors of the USSR. Among them the first and the third had been of a crucial impact. The second summit noted rather a lack of interest in the program on the part of Western European States. The fourth meeting of the leaders of the States was characterized by a significant adjustment of approaches. The fifth summit, held in 2017, set the tasks of the «new generation», formed in the "post-Ukrainian world».

Key words: European Union, Eastern partnership, enlargement, neighborhood policy, adaptation program, foreign policy.

DOI: http://dx.doi.org/10.15211/vestnikieran620182635 